\title{
Mulheres no tráfico de drogas Retratos da vitimização e do protagonismo feminino
}

\author{
Women in drug trafficking \\ Pictures of female victimization and protagonism
}

\author{
Mariana Barcinski* \\ Sabrina Daiana Cúnico**
}

\begin{abstract}
Resumo: A partir das histórias relatadas por duas mulheres com um longo envolvimento passado na rede do tráfico de drogas em favelas do Rio de Janeiro, este ensaio tem por objetivo problematizar a tradicional vitimização e submissão com que usualmente a literatura caracteriza as trajetórias de mulheres criminosas. O que as histórias dessas mulheres atestam é que a possibilidade de ocuparem posições masculinas e obterem o respeito e o prestígio atribuído aos homens traficantes são grandes motivadores para o ingresso e a permanência de mulheres na rede do tráfico de drogas. Neste sentido, é pela apropriação de características e comportamentos masculinos, tais como a violência e a submissão de outras mulheres, que elas confirmam seu limitado poder.
\end{abstract}

Palavras-chave: Mulheres. Tráfico de drogas. Vitimização. Protagonismo.

Abstract: Through the stories of two women with a long term involvement in the drug trafficking network in slums in Rio de Janeiro, this essay has the goal of problematizing the traditional victimization and submission with which the literature usually characterizes the trajectories of criminal women. What the stories of these two women attest is that the possibility of assuming male roles, as well as achieving the respect and prestige attributed to male gangsters are great motivators in their decision to engage and to remain in the activity. In this sense, it is by appropriating from male characteristics and behaviors, such as violence and submission of women, that these women confirm their limited power.

Keywords: Women. Drug trafficking. Victimization. Protagonism.

* Doutora em Developmental Psychology pela Clark University (Worcester, Massachusetts, Estados Unidos), professora da Faculdade de Psicologia da Pucrs, Porto Alegre, RS, Brasil. $<$ mariana.barcinski@pucrs.br>.

**Mestre em Psicologia pela UFSM (Santa Maria, RS, Brasil), doutoranda em Psicologia na Pucrs, Porto Alegre, RS, Brasil, professora da Faculdade de Psicologia do Cesuca Inedi, Cachoeirinha, RS, Brasil.<sabrinacunico@yahoo.com.br>. 


\section{Introdução}

O presente ensaio tem por finalidade versar sobre as especificidades da criminalidade feminina, problematizando os argumentos que usualmente justificam o apagamento das mulheres dos estudos em criminologia. Segundo tais estudos, a ausência ou o pouco interesse teórico sobre os crimes femininos se deve ambos à baixa taxa de crimes nos quais as mulheres estão diretamente envolvidas e à percepção de que esses crimes são caracterizados por menor gravidade e violência. Análises sobre os crimes femininos restringem seu entendimento aos aspectos biológicos e psicológicos das mulheres ofensoras, ignorando a determinação econômica, social e cultural que, em grande medida, dá sentido à transgressão feminina (Carlen, 1993; Gregory, 1993; Heidensohn, 1985; Schram e Koons-Witt, 2004).

Ainda, ao se ocuparem do envolvimento de mulheres em atividades criminosas, autores enfatizam a participação dos homens na iniciação criminosa feminina (Almeida, 2001; Barcinski, 2008; Barcinski et al., 2013). Neste sentido, o comportamento das mulheres seria resultado da associação afetiva ou sexual com parceiros criminosos. Posicionadas exclusivamente como vítimas dos homens ao seu redor, essas mulheres se tornam cúmplices dos crimes cometidos por seus parceiros e eventualmente pagam, através do encarceramento, por um comportamento socialmente não reconhecido como feminino.

Os discursos hegemônicos situam homens e mulheres em polos opostos no que se refere à possibilidade de engajamento destes em atividades violentas. Portanto, em grande medida a escassez de literatura sobre a violência e/ou criminalidade feminina se justifica por reconhecermos socialmente a mulher como vítima, mas não como perpetradora de violência (Narvaz e Koller, 2006). A docilidade e a fragilidade naturais das mulheres as tornariam menos capacitadas a cometer crimes do que os homens (Faria, 2008). Neste sentido, as mulheres criminosas são consideradas duplamente transgressoras: da lei e das prescrições sociais de gênero, que posicionam homens, não mulheres, como violentos.

Teorias têm enfocado preferencialmente as esferas psicológicas e biológicas, que justificariam a baixa incidência dos crimes femininos pela falta de propensão e habilidade das mulheres para a transgressão (Schram e KoonsWitt, 2004). Investigar as diferenças entre as práticas violentas cometidas por homens e mulheres, bem como as especificidades da criminalidade feminina, no entanto, constitui passo importante para reconhecer o papel de gênero na prescrição de comportamentos em nossa sociedade. 
Steffensmeier e Allan (1996) apontam, como mencionado acima, para o caráter relacional dos crimes cometidos por mulheres. Segundo os autores, mulheres envolvidas em atividades criminosas tendem a enfatizar seu papel como cuidadoras, justificando seu envolvimento no crime como estratégia de proteção de suas relações afetivas. Em estudo conduzido com mulheres com longa história de envolvimento na rede do tráfico de drogas no Rio de Janeiro, Barcinski (2008) afirma a centralidade de parceiros, filhos e mães nos argumentos das participantes para se engajarem em tal atividade. A provisão material para a família, especialmente quando da ausência da figura masculina no núcleo familiar, bem como a manutenção de uma relação afetiva com parceiro envolvido na rede do tráfico são apontadas como motivadoras do ingresso na atividade.

Em estudo sobre o perfil de mulheres no Estado do Rio de Janeiro, Soares e Ilgenfritz (2002) chamam a atenção para o alto nível de vitimização em suas trajetórias de vida. A vitimização feminina em diversos níveis - do abuso e negligência à extrema pobreza -, portanto, resultaria em um processo de criminalização peculiar às mulheres. Assis e Constantino (2001), ao investigarem os impactos da vitimização na trajetória de meninas em conflito com a lei enfatizam o abandono, o abuso emocional e agressão física como características recorrentes nas histórias de vida destas meninas.

$\mathrm{O}$ que tais explicações acima - focadas exclusivamente na vitimização feminina - deixam intocadas é o papel ativo das mulheres que decidem tomar parte em atividades criminosas. O protagonismo e a atividade femininas são ignorados em argumentos que se centram na inabilidade feminina para o crime, na natural propensão das mulheres a protegerem aqueles ao seu redor ou na relação de causalidade linear entre violência sofrida e violência perpetrada pelas mulheres.

Não se trata obviamente de ignorar a vitimização das mulheres, nem tampouco o seu papel nas escolhas (ou na falta de escolhas) das traficantes femininas. Gregory (1993) denuncia, por exemplo, a ingenuidade contida no argumento da prática criminosa como resultante da maior liberdade conquistada no mundo público pelas mulheres. $\mathrm{O}$ argumento, segundo o qual a criminalidade feminina expressaria o "lado negro da liberação feminina", sustenta que as mulheres têm demandado iguais oportunidades no mundo legal e ilegal de trabalho. Em 1975, Freda Adler já afirmava que a liberação das mulheres teria concedido a elas o direito de se comportar como os homens, incluindo o direito de serem violentas e propensas ao crime como eles.

No entanto, apesar do caráter transgressor do tráfico de drogas, por exemplo, as mulheres traficantes não podem definitivamente ser consideradas 
emancipadas, autônomas ou empoderadas. Assim como no mundo do trabalho formal, mulheres usualmente desempenham funções subordinadas aos homens no crime organizado. Tal como as crianças, mulheres são arregimentadas para o desempenho de tarefas secundárias ou mais perigosas, tais como transportar drogas de um ponto de venda a outro. Por supostamente levantarem menos suspeitas acerca de seus comportamentos, mulheres e crianças são usadas pelas organizações criminosas para a consecução destas tarefas menos valorizadas social e financeiramente (Barcinski, 2008).

A discussão acima resulta em um cenário da criminalidade feminina em que vitimização e protagonismo convivem nas escolhas e nas histórias de vida de mulheres envolvidas com atividades criminosas. O reducionismo dos argumentos que situam as mulheres ora como vítimas passivas, ora como indivíduos finalmente emancipados das amarras culturais e sociais, ignora a complexidade das trajetórias de mulheres envolvidas com a criminalidade.

Baseando-nos na história de vida e no discurso de duas mulheres envolvidas na rede do tráfico em favelas no Rio de Janeiro, o presente capítulo tem como objetivo problematizar o papel exclusivo de vítimas usualmente atribuído às "mulheres criminosas". As trajetórias de Denise e Vanessa, duas mulheres com uma longa história de envolvimento no tráfico de drogas, evidenciam simultaneamente a vitimização e o protagonismo que marcam suas escolhas. Vítimas de uma estrutura social que limita suas escolhas de vida e envolvidas em relações afetivas (com parceiros e amigos) que, supostamente, as "empurraram" para o mundo do crime, essas duas mulheres expressam o prazer, a liberdade e a satisfação de terem ocupado lugares e desempenhado funções tradicionalmente desempenhadas pelos homens na rede do tráfico de drogas.

O entendimento das histórias de Denise e Vanessa, especialmente no que se refere às possibilidades de estas mulheres serem reconhecidas como diferentes (e superiores) às mulheres ao seu redor - demandam o entendimento de gênero como um conceito relacional. Neste sentido, a forma como essas duas personagens se situam em suas escolhas de vida apontam para as prescrições e restrições socialmente construídas para homens e mulheres em nossa sociedade, bem como para a limitada possibilidade de rompimento com tais prescrições.

\section{Gênero como conceito relacional}

Mulheres e homens possuem diferentes modos e possibilidades de inserção e trânsito no campo social, incluindo o envolvimento em atividades criminosas. Estas diferenciações que marcam a vida de homens e mulheres são 
sustentadas, fundamentalmente, pelos estereótipos de gênero, ou seja, pelas atribuições que expressam os padrões de masculinidade e feminilidade a serem seguidos.

De acordo com Gomes (2008), os modelos de gênero se estabelecem a partir de um panorama relacional, em que o que é entendido culturalmente como masculino só produz sentido a partir do feminino e vice-versa. As identidades de homens e mulheres se afirmam, então, por meio das aproximações e afastamentos em relação às atitudes, comportamentos e emoções a serem seguidos por cada gênero.

A partir dos requisitos associados ao ideal de masculinidade, tais como a força, o poder sobre os mais fracos (sendo eles mulheres ou outros homens), a coragem, a não passividade e a resistência, entende-se que a valorização deste padrão, que exige a supressão de sentimentos e de certas formas de expressão, tem o potencial de impulsionar e legitimar reações violentas dos homens. Ao passo que as características associadas à feminilidade - recato, pudor, docilidade e passividade, por exemplo - são frequentemente utilizadas para justificar a posição da mulher como vítima, nunca como perpetradora de violência.

Portanto, é possível afirmar uma forte articulação entre masculinidade e violência, o que faz com que atos violentos perpetrados por homens sejam vistos como resultantes da própria condição do masculino. Sendo assim, num contexto em que se legitima a associação entre o ser masculino e o ser violento, "as relações de gênero podem ser construídas e reproduzidas a partir de uma lógica de que a violência seria a referência para se diferenciar o homem da mulher" (Gomes, 2008, p. 240).

Ao propor a inserção da violência contra a mulher no amplo espectro da violência de gênero, Saffioti $(1997 ; 1999 ; 2001)$ critica a corrente vitimista de pensamento, que interpreta a mulher vítima de violência como não-sujeito, isto é, incapaz de reagir e de oferecer resistência nos casos de violência perpetrada pelos homens. Para a autora, embora muitos homens dispensem às mulheres um tratamento de não-sujeitos, fazendo com que estas se sintam como tais, as relações sociais só se dão entre sujeitos. Não há a possibilidade de que uma pessoa se converta em objeto em uma relação, ainda que seja assim tratada. Portanto, as mulheres que sofrem violência são vítimas, mas não passivas.

Salientamos, portanto, a importância de adotarmos uma perspectiva relacional da violência, de modo a evitar o reforço da dicotomia docilidadefeminina e agressividade-masculina (Medrado e Lyra, 2008). Ao assumirmos a posição que considera a mulher sempre como vítima passiva e o homem sempre como algoz, não abrimos espaço para que as relações de poder e as 
prescrições acerca dos comportamentos de homens e mulheres na sociedade possam ser ressignificadas e transgredidas.

No que se refere ao entendimento da criminalidade feminina, a adoção de uma perspectiva relacional de gênero - que entende as prescrições às mulheres como estabelecidas em oposição às prescrições socialmente destinadas aos homens - nos permite entender como Vanessa e Denise simultaneamente se apropriam e resistem às normativas de gênero na construção de suas trajetórias criminosas. O envolvimento destas duas mulheres na rede do tráfico de drogas expressa a vitimização e a submissão feminina e, ao mesmo tempo, a apropriação de características e prerrogativas do mundo masculino. Denise e Vanessa são simultaneamente vítimas e protagonistas em suas histórias, reafirmando e contestando o lugar de submissão e passividade socialmente destinado às mulheres.

\section{A história de Denise}

Denise tem 30 anos, é negra e mora em uma das maiores favelas do Rio de Janeiro. É mãe de três meninas, com idades de 7, 11 e 16 anos, cada qual fruto de um relacionamento diferente. É casada com um homem encarcerado pelo envolvimento no tráfico de drogas. O companheiro liga para ela frequentemente da prisão, ameaçando a sua vida e exigindo que ela o visite semanalmente. Embora, de acordo com a "lei do tráfico", Denise deva se manter fiel ao marido durante o período de encarceramento, ela expressa seu desejo em terminar esta relação.

Denise esteve envolvida no tráfico de drogas durante 15 anos, num período que se estendeu dos seus 13 aos 28 anos. No "mundo do tráfico", ela representa um caso excepcional, porque ocupava uma posição tradicionalmente ocupada por homens e de grande prestígio: a de gerente de uma "boca de fumo", nome popularmente dado aos pontos de venda de drogas no varejo. Ela era responsável pelo comércio das drogas lá vendidas, bem como pelo comando de homens e mulheres que trabalhavam sob as suas ordens. Ao longo de todas as suas entrevistas, Denise expressava muito orgulho do poder que tinha como traficante.

Foi justamente a busca pelo poder e o desejo de se sentir temida e poderosa, que motivou a entrada dela no tráfico de drogas. Em seu discurso, Denise enfatizava o medo que causava em seus funcionários e a possibilidade de subjugar especialmente outras mulheres. É desta forma que ela justificava o pra zer de ser chefe: "me sentia superior. [...] Todas tinham que ser submissas a mim". Embora tivesse homens também sob seus mandos, é o exercício do poder e do domínio sobre outras mulheres que caracterizava Denise como traficante. 
No entanto, o inegável poder conquistado por Denise na rede do tráfico de drogas naquela localidade, atestado pelo número de funcionários que tinha para servi-la, não se deu sem sofrimento e sem abnegação. O relato de sua ascensão como traficante evidencia uma mulher que teve que realizar tarefas secundárias, potencialmente humilhantes e de risco, a fim de ganhar a confiança dos homens traficantes. Seu poder e posição de destaque na atividade foram conquistados principalmente através da submissão aos homens traficantes, cozinhando e mantendo relações sexuais com os líderes de facções e, por fim, negociando armas e drogas com traficantes de outras favelas. $\mathrm{Ou}$ seja, o envolvimento de Denise no tráfico de drogas foi, na realidade, uma consequência de seu relacionamento com homens traficantes, marcada pelo desempenho de tarefas tipicamente femininas, tais como cozinhar, ter relações sexuais e fazer pequenos favores para os homens.

Embora não fosse a única mulher envolvida com o tráfico em sua comunidade, Denise se sentia superior às outras por conta da posição de prestígio que ocupava na atividade e por ser reconhecida como a mulher que realizava "missões impossíveis", em suas palavras. A afirmação de sua peculiaridade como mulher traficante culmina com a afirmação de Denise de que muitas mulheres decidiram abandonar o tráfico de drogas em sua localidade após ela ter tomado esta mesma decisão.

Portanto, a construção da personagem Denise traficante se dá primordialmente através da afirmação da sua diferença, distância e superioridade em relação a outras mulheres. Denise era melhor, mais temida, mais corajosa e mais confiável do que outras mulheres envolvidas no tráfico de drogas. No entanto, sua história na atividade - tal como narrada por ela - traz a marca da submissão que ela também experimentou, ao fazer pequenos favores a fim de ganhar a confiança dos homens (esses sim os líderes legitimados na atividade). Portanto, considerando a posição marginal das mulheres nas favelas, e especialmente dentro de tráfico de drogas, o poder de Denise era experimentado dentro de limites rígidos, circunscrito principalmente ao exercício de subjugação de outras mulheres.

\section{A história de Vanessa}

Vanessa tem 26 anos, é parda e vive em uma grande favela do Rio de Janeiro, onde também moram seus pais e o irmão adotivo de oito anos. Em função do seu envolvimento com o tráfico de drogas, saiu da casa dos pais aos 16 anos. Ela é solteira e não possui filhos. Vanessa atuou no tráfico de drogas por oito anos, executando desde tarefas secundárias, até assumir gradualmente mais responsabilidades e riscos, segundo seu relato. A ascensão nesta atividade 
é descrita como o resultado de seu trabalho árduo e de sua lealdade aos colegas de facção criminosa a qual pertencia.

De acordo com Vanessa, o tráfico de drogas é altamente democrático, uma vez que qualquer pessoa pode se engajar nesta atividade, independentemente de raça, classe social e nível de escolaridade. Apesar de este seu argumento não incluir uma apreciação sobre como - e se - as prescrições de gênero influenciam os papeis desempenhados, ela implicitamente afirma que os criminosos homens e mulheres têm o mesmo status dentro da atividade. $\mathrm{O}$ fato de as mulheres serem usualmente exploradas pelos homens, desempenhando funções mais arriscadas e menos prestigiosas na rede do tráfico de drogas, não é apontado por Vanessa como elemento que problematize o caráter democrático da atividade.

Ao comentar sobre sua própria trajetória, Vanessa, tal como Denise, enfatiza sua distinção em relação a outras mulheres traficantes. Além do aspecto financeiro, que ela apresenta como uma das principais razões por ter optado pelo ingresso no tráfico, Vanessa sentia orgulho em se reconhecer e em ser reconhecida como uma mulher diferente e em ter a atenção dos homens de sua facção: "eu achava diferente uma mulher - a gente praticamente não via nenhuma mulher no tráfico. Ai os garotos também já gostava".

A distância que Vanessa imprime em relação a ela e as outras mulheres do tráfico é sustentada por evidências de sua proximidade em relação aos homens traficantes. Enquanto a maioria das mulheres trabalhava vendendo drogas nas bocas de fumo, ela se posicionava como "um dos caras": "andava armado, dava tiro, trocava tiro. Tudo com eles e eu fazia ali, entendeu? Não ficava ali igual a elas, só sentada vendendo [...]. Era como se eu fosse um soldado mesmo, entendeu, do tráfico".

$\mathrm{Na}$ organização do tráfico, os soldados são responsáveis pela segurança das bocas de fumo (locais onde as drogas são vendidas no varejo). Os soldados portam armas e se arriscam constantemente em combates com a polícia e com facções criminosas rivais. Ser um soldado, portanto, trocando tiros como os homens, tornava Vanessa naturalmente diferente das mulheres que apenas vendiam drogas, sentadas nas bocas de fumo. A disposição de se arriscar, de tomar parte em combates que envolviam risco, aproximava Vanessa do universo dos homens. Importante notar que no trecho de discurso acima transcrito, em que ela se apresenta como um soldado, Vanessa utiliza referentes masculinos ao se referir a sua prática: "andava armado".

Ser "um dos caras" significa, portanto, estabelecer simultaneamente sua distinção em relação às mulheres e sua identificação com os homens traficantes. Também como Denise, é principalmente através da subjugação, da submissão 
e da distância estabelecida em relação a outras mulheres que Vanessa afirma sua especificidade e seu poder. Ao descrever o respeito que adquiria ao ser reconhecida como uma traficante temida, ela constrói o seguinte discurso:

mas eu também gostava do respeito. [...] era legal assim eu ir no baile aí, caramba, o baile cheião, um montão de vagabunda andando e eu lá no meio. Caraca, todo mundo parava pra olhar. Caraca, ai só ouvia cochichando: 'caraca, olha aquela garota'.

Vanessa claramente expressa o prazer de entrar no baile portando um fuzil e de se sentir respeitada e temida; respeito evidenciado pelos olhares que conquistava e pelos comentários que ouvia nestas ocasiões. No entanto, é especialmente o impacto que causa nas mulheres - pejorativamente chamadas de "vagabundas" - que ela enfatiza. Nestas ocasiões, Vanessa firmava sua autoridade sacando sua arma e mandando outras mulheres deitarem no chão, unicamente para perceber nelas o medo e o respeito que tanto prezava. Como "um dos caras", Vanessa submete as mulheres ao seu redor, afirmando em suas práticas a violência como prerrogativa do masculino e a submissão, o medo e a deferência como características do feminino.

\section{Considerações finais}

Embora as histórias de Denise e Vanessa sejam marcadas por diferenças no que se refere às motivações para a entrada no tráfico de drogas e à forma como elas se constroem discursivamente como traficantes, o aspecto central de suas trajetórias parece ser a forma como a inserção em uma atividade socialmente reconhecida como masculina concede as duas uma posição diferenciada em relação às mulheres em seu entorno. Ambas reconhecem suas experiências pregressas na atividade como não convencionais, no sentido de estas posicionarem-nas próximo dos homens e distantes das mulheres envolvidas no tráfico de drogas. De acordo com seus relatos, Denise e Vanessa foram "traficantes de verdade", empunhando armas, entrando em combates, carregando drogas e armas entre diferentes favelas, enfim, assumindo destemidamente os riscos que somente os homens são preparados a assumir. $\mathrm{E}$ ao se portarem e, principalmente serem reconhecidas como "traficantes de verdade" (como os homens), as duas mulheres experimentavam o prazer, o prestígio e o poder tradicionalmente destinado aos homens.

Quando focamos nos discursos hegemônicos acerca dos papeis de gênero, é de alguma forma surpreendente que Denise e Vanessa afirmem seu poder portando armas e causando medo às pessoas. De acordo com feministas que versam sobre a subjetividade feminina, tais como Gilligan (1982) e 
Miller (1986), as mulheres experimentam o poder usualmente através das relações e conexões afetivas que são capazes de estabelecer com pessoas em suas vidas. Portanto, é principalmente a habilidade de formar e manter vínculos que concede poder e prestígio às mulheres.

Em grande medida, a forma como Denise e Vanessa caracterizam o poder como traficantes reflete o conflito entre ser mulher e experimentar o poder de uma forma tão obviamente masculina: carregando armas, causando medo e subjugando outros. O que suas trajetórias atestam é que as duas jamais experimentaram este poder de forma absoluta, como uma prerrogativa adquirida de forma definitiva e que prescindisse de negociação constante. É quase que exclusivamente na comparação com outras mulheres que elas se sentem especiais: mais fortes, mais corajosas, mais autorizadas ao exercício da força e da subjugação.

Portanto, como mulheres, Denise e Vanessa exercem seu constrangido poder sobre outras mulheres, percebidas como mais fracas e vulneráveis de alguma forma. Em um contexto - do tráfico de drogas e das periferias urbanas - que afirma o poder como uma propriedade exclusiva dos homens (Cecchetto, 2004) -, é se alinhando a eles que as duas constroem suas identidades como mulheres temidas e perigosas.

O constrangimento ao exercício pleno do poder feminino nos aponta, como discutido no início deste ensaio, para o caráter relacional de gênero. Se por um lado as experiências de Denise e Vanessa obviamente nos fazem questionar a vitimização e a submissão através das quais as "mulheres criminosas" têm sido descritas na literatura, é somente a partir dos discursos hegemônicos que constroem a masculinidade e a feminilidade que podemos fazer sentido deste limitado poder exercidos por elas.

Embora Denise e Vanessa tenham rompido barreiras no que tange à expectativa do envolvimento feminino no tráfico de drogas, são inegáveis as limitações e barreiras impostas ao exercício pleno de seu poder. Ao recorrer à literatura, encontramos em Saffioti (1989) a referência ao "pequeno poder" que atestamos nas histórias destas duas mulheres. A autora acima afirma que a impotência pode ser considerada como a outra face do poder. As mulheres, embora socializadas para lidar com este sentimento, frequentemente buscam formas de superá-lo e transgredi-lo. É esse movimento, resultante da incapacidade de experimentar a impotência, que a autora denomina de síndrome do pequeno poder. Percebendo seu poder como limitado em relação ao poder masculino, a mulher subjuga aqueles que expressam menor resistência, tais como crianças e outras mulheres. 
O que depreendemos, portanto, da experiência destas duas mulheres traficantes é que o poder feminino, não legitimado socialmente, é exercido de formas sutis, menos explícitas ou abertamente agressivas como o é o poder masculino. Ser reconhecida como alguém que exerce funções e ocupa posições destinadas aos homens, bem como ter sob seu comando outras mulheres concede uma posição privilegiada às traficantes femininas. Portanto, convivem nas histórias e nos discursos de Denise e Vanessa a vitimização feminina evidenciada pela submissão aos modelos hegemônicos de masculinidade e feminilidade e pelo constrangimento ao exercício de seu poder - e o protagonismo feminino, refletido no desejo de engajamento na atividade, bem como no obvio prazer experimentado ao serem reconhecidas como mulheres diferenciadas em suas comunidades.

\section{Referências}

ADLER, Freda. Sisters in crime. New York: McGraw Hill, 1975.

ALMEIDA, Vanessa Ponstinnicoff de. Repercussões da violência na construção da identidade feminina da mulher presa: um estudo de caso. Psicologia ciência e profissão, v. 26, n. 4, p. 604-619, 2006.

ASSIS, Simone Gonçalves de; CONSTANTINO, Patrícia. Filhas do mundo: infração juvenil e feminina no Rio de Janeiro. Rio de Janeiro: Editora Fiocruz, 2001.

BARCINSKI, Mariana. Women in drug trafficking: the identity construction of Brazilian reformed criminals. Saarbrücken: VDM, 2008.

BARCINSKI, Mariana; CAPRA-RAMOS, Carine; WEBER, João; DARTORA, Tamires. O Marianismo e a vitimização de mulheres encarceradas: formas alternativas de exercício do poder feminino. Ex aequo, n. 28, p. 87-100, 2013.

CARLEN, Pat. Women, crime, feminism and realism. In: Stevi Jackson et al. (orgs.). Women's studies: essential readings. New York: New York University Press, 1993. p. 314-316.

CECCHETTO, Fátima. Violência e estilos de masculinidade. Rio de Janeiro: FGV, 2004.

FARIA, Thaís Dumêt. Mulheres no tráfico de pessoas: vítimas e agressoras. Cadernos Pagu, n. 31, p. 151-172, $2008<10.1590 /$ S0104-83332008000200008>.

GILLIGAN, Carol. In a different voice: psychological theory and women's development. Cambridge: Harvard University Press, 1982.

GOMES, Romeu. A dimensão simbólica da violência de gênero: uma discussão introdutória. Athenea Digital, n. 14, p. 237-243, 2008.

GREGORY, Jeanne. Sex, class and crime. In: Stevi Jackson et al. (orgs.), Women's studies: essential readings. New York: New York University Press, 1993. p. 316-317.

HEIDENSOHN, Frances. Women and crime. New York: New York University Press, 1985 . 
MEDRADO, Benedito; LYRA, Jorge. Por uma matriz feminista de gênero para os estudos sobre homens e masculinidades. Estudos feministas, v. 16, n. 3, p. 809-840, $2008<10.1590 /$ S0104-026X2008000300005>.

MILLER, Jean Baker. Towards a new psychology of women. Boston: Beacon Press, 1986.

NARVAZ, Martha Giudice; KOLLER, Silva Helena. Famílias e patriarcado: da prescrição normativa à subversão criativa. Psicologia \& Sociedade, v. 18, n. 1, p. 49-55, $2006<10.1590 /$ S0102-71822006000100007>.

SAFFIOTI, Heleieth Iara Bongiovani. A síndrome do pequeno poder. In: Maria Amelia Azevedo; Viviane Nogueira de Azevedo Guerra (orgs.). Crianças vitimizadas: a síndrome do pequeno poder. São Paulo: Iglu Editora, 1989. p. 13-21.

SAFFIOTI, Heleieth Iara Bongiovani. Violência de gênero: o lugar da práxis na construção da subjetividade. Lutas Sociais, n. 2, p. 59-79, 1997.

SAFFIOTI, Heleieth Iara Bongiovani. Já se mete a colher em briga de marido e mulher. São Paulo em Perspectiva, v. 13, n. 4, p. 82-91, $1999<10.1590 /$ S010288391999000400009>.

SAFFIOTI, Heleieth Iara Bongiovani. Contribuições feministas para o estudo da violência de gênero. Cadernos Pagu, n. 16, p. 115-136, 2001.

SCHRAM, Pamela. J.; KOONS-WITT, Barbara. Gendered (in)justice: theory and practice in feminist criminology. Long Grove: Waveland Press, 2004.

SOARES, Barbara Musumeci; ILGENFRITZ, Iara. Prisioneiras: vida e violência atrás das grades. Rio de Janeiro: Garamond, 2002.

STEFFENSMEIER, Darrell; ALLAN, Emilie. Gender and crime: toward a gendered theory of female offending. Annual Review of Sociology, v. 22, p. 459-487, 1996 $<10.1146$ /annurev.soc.22.1.459>.

Recebido em: 12 out. 2015

Aprovado em: 23 nov. 2015

Autora correspondente:

Mariana Barcinski

Faculdade de Psicologia, Pucrs

Av. Ipiranga 6681 - Prédio 11

90619-900 Porto Alegre, RS, Brasil 